\title{
Collision Aversion Model for Inland Water Transportation: Cost Benefit Analysis Model
}

\author{
O. Sulaiman, A.S.A. Kader, A.H., Saharuddin
}

\begin{abstract}
Inland water transportation project is considered today as one of the mitigation option available for humanity to curb carbon footage. Collision in inland water transportation represents the biggest treat to inland water transportation; its occurrence is very infrequent but has grave consequence that makes its avoidance a very imperative factor. The nature of the threat of collision can be worrisome, as they can lead to loss of life, damage to environment, disruption of operation, injuries, instantaneous and point form release of harmful substance to water, air and soil and long time ecological impact. However, the development of complex system like inland water transportation and collision avoidance system also needs to meet economic sustainability for decision requirement related to collision avoidane. This makes analysing and quantifying occurrence scenarios, consequence of accident very imperative for reliable and sustainable design for exercise of technocrat stewardship of safety and safeguard of environmental. This paper discusses the cost benefit analysis for risk control option required for operational, societal and technological change decision for sustainable inland water transportation system. The paper presents the result of predictive cost for collision aversion aversion for in River Langat waterways development.
\end{abstract}

\section{INTRODUCTION}

Collision risk is a product of the probability of the physical event occurrence as well as losses that include damage, loss of life and economic losses. Accident represent risk because they expose vessel owners and operators as well as the public to the possibility of losses such as vessel, cargo damage, injuries, loss of life, environmental damage, and obstruction of waterways. Collision accident scenarios carry heavy consequence, thus its occurrence is infrequence. Complete risk and reliability modelling require frequency estimation, consequence quantification, uncertainties and cost benefit analysis of the holistic system [1,2]. Like the frequency and consequence analysis, collision cost data are hard to come by, however, whatever little data that is available should be made meaningful as much as possible through available tools especially system based predictive tools required for decision support system necessary mitigation decision for sustainable and reliable waterways. Inherently, accident data for waterway are few that make probabilistic and stochastic methods the best preliminary method to analyze the risk in waterways. Other information relating to channel vessel and environment employed in the risk process, lacking

O. Sulaiman, A.S.A. Kader, A.H., Saharuddin are University Malaysia Terengganu, 21030, Kuala Terengganu, Terengganu, Malaysia (email: O.sulaiman@umt.edu.my). information about the distribution of transits during the year, or about the joint distribution of ship size, flag particular and environmental conditions become derivative from probabilistic and stochastic estimation in the model. Result from such model could further be enhanced through simulation methods as required. This paper discusses cost benefit analysis to support risk control option for waterways predictive collision risk aversion model. [3, 4]

\section{BACKGROUND}

The case study considered for this study is Langat River, $220 \mathrm{~m}$ long navigable inland waterway that has been considered underutilized due to lack of use of the water resources up to its capacity. Personal communication, survey and river cruise on Langat River revealed that collision remain the main threat of the waterways despite less traffic in the waterways.. Data related to historical accidents, transits, and environmental conditions are collected. Barge and tug of capacity 5000T and 2000T are currently plying this waterway at draft of 9 and 15 respectively. Safety associated with small craft is not taken into account. Figure 1 and 2 channel width parameter required for damage analysis. Vessel width parameter plays a very important role in collision scenario and potential damage. Vessel movement for the case under consideration currently has no vessel separation system. However, there is traffic movement from both inbound and outbound navigation in the channel. The same type of barge size is considered for the estimation work.

\section{SAFETY AND ENVIRONMENTAL RISK FOR IWT}

Risk and reliability based model aim to develop innovative methods and tools to assess operational, accidental and catastrophic scenarios. It requires accounting for the human element, and integrates them as required into the design environment. Risk based design entails the systematic integration of risk analysis in the design process. It target safety and environment risk prevention and reduction as a design objective. To pursue this activity effectively, an integrated design environment to facilitate and support a holistic risk approach to ship and channel design is needed. A total risk approaches which enable appropriate trade off for advanced sustainable decision making. Waterways accident falls under scenario of collision, fire and explosion, flooding, grounding. Collision carries the highest percentage, more frequent it is cause by $[5,6]$ :

i. Loss of propulsion

ii. Loss of navigation system 
iii. Loss of mooring function and

iv. Loss of Other accident from the ship or waterways

Risk based design entails the systematic risk analysis in the design process targeting risk preventive reduction. It facilitates support for total risk approach to ship and waterways design. Integrated risk based system design requires the availability of tools to predict the safety, performance and system components as well as integration and hybridisation of safety element and system lifecycle phases. The risk process begins with definition of risk which stands for the measure of the frequency and severity of consequence of an unwanted event (damage, energy, oil spill). Risk is defined as product of probability of event occurrence and its consequence [7].

Risk $(\mathrm{R})=$ Probability $(\mathrm{P}) \mathrm{X}$ Consequence $(\mathrm{C})$ 3.1

Incidents are unwanted events that may or may not result to accidents. Necessary measures should be taken according to magnitude of event and required speed of response should be given. Accidents are unwanted events that have either immediate or delayed consequences. Immediate consequences variables include injuries, loss of life, property damage, and persons in peril. Point form consequences variables could result to further loss of life, environmental damage and financial costs. Effective risk assessments and analysis required three elements highlighted in the relation below.

Risk modeling $=$ Framework + Models + Process

Eq. 1

Reliability based verification and validation of system in risk analysis should be followed with creation of database and identification of novel technologies required for implementation of sustainable system.

\section{A. Risk Framework}

Risk framework provides system description, risk identification, criticality, ranking, impact, possible mitigation and high level objective to provide system with what will make it reliable. The framework development involves risk identification which requires developing understanding the manner in which accidents, their initiating events and their consequences occur. Risk framework should be developed to provide effective and sound risk assessment and analysis. The process requires accuracy, balance, and information that meet high scientific standards of measurement. The information should meet requirement to get the science right and getting the right science. The process requires targeting interest of stakeholder including members of the port and waterway community, public officials, regulators and scientists. Transparency and community participation helps ask the right questions of the science and remain important input to the risk process, it help checks the plausibility of assumptions and ensures that synthesis is both balanced and informative. Employment of quantitative analysis with required insertion of scientific and natural requirements provide analytical process to estimate risk levels, and evaluating whether various measures for risk are reduction are effective[8].

\section{B. Safety and Environmental Risk and Reliability Model (SERM)}

There is various risk and reliability tools available for risk based methods that fall under quantitative and qualitative analysis. Choice of best methods for reliability objective depends on data availability, system type and purpose. However employment of hybrid of methods of selected tool can always give the best of what is expect of system reliability and reduced risk.

\section{SERM Process}

SERM intend to address risks over the entire life of the complex system like IWT system where the risks are high or the potential for risk reduction is greatest. SERM address quantitatively, accident frequency and consequence of IWT. Other risk and reliability components including human reliability assessment which is recommended to be carried out separately as part of integrated risk process. Other waterways and vessel requirement factors that are considered in SERM model are [9]:

\section{i. Construction}

ii. Towing operations and abandonment of ship

iii. Installation, hook-up and commissioning

iv. Development and major modifications

Integrated risk based method combined various technique as required in a process. Table 2 shows available risk based design for techniques. This can be applied for each level of risk. Each level can be complimented by applying causal analysis (system linkage), expert analysis (expert rating), and organizational analysis (Community participation) in the risk process. Figure 3 shows SERM model and components of cost sustainability analysis

\section{RELIABILITY AND VALIDATION ANALYSIS:}

System reliability could be determined through the following analysis [10]:

1) Standard Deviation: Accident means, variance and standard deviation from normal distribution

2) Stochastic Analysis: Accident average and projection rates per year calculation can be reliability projection for the model. Poison distribution, standards distribution for and binomial distribution could be analyzed for required prediction and system capability. Poison distribution involves the likelihood of observing $\mathrm{k}$ event in time interval $\mathrm{T}$ is poison distribution.

3) Comparing the model behaviour apply to other rivers of relative profile and vessel particular.

4) Triangulating analysis of sum of probability of failure from subsystem level failure analysis

5) System improvement, for example Traffic Separation Scheme (TSS) Implementation effectiveness, could achieve reduction in head collision. This can be done through integration of normal distribution along width of the waterways and subsequent implementation frequency model.

6) Comparing the model behaviour applied to other rivers of relative profile and vessel particular 


\section{Risk Cost BENEFIT ANALYSIS (RCBA) AND RISK CONTROL OPTION MODEL PROCESS}

RCBA is use to deduce mitigation, options selection and proposed need for technology, reliability, new regulations and sustainability required to be modeled for effective mitigation options. RCBA involves quantification of cost effectiveness that provides basis for decision making about identified RCO. This includes the net or gross and discounting values for cost of equipment, redesign and construction, documentation, training, inspection maintenance drills, auditing, regulation, reduced commercial used and operational limitation (speed, loads). Benefit could include reduced probability of fatality, injuries, serenity, negative effects on health, severity of pollution and economic losses. Identified types of cost and benefits for each risk control option according to RCBA for the entities which are influenced by each option can be deduced. And also identification of the cost effectiveness expressed in terms of cost per unit risk reduction [11]. 6.1

\section{A. Risk Cost Option (RCO) and Cost Effective Analysis (CEA)}

Risk control measures are used to group risk into a limited number of well practical regulatory and capability options. Risk Control Option (RCO) aimed to achieve (David, 1996):

i. Preventive: reduce probability of occurrence

ii. Mitigation: reduce severity of consequence

RCO could follow the following generic approach:

i. General approach: controlling the likelihood of initiation of accidents. be effective in preventing several different accident sequences; and

ii. Distributed approach: control of escalation of accidents and the possibility of influencing the later stages of escalation of other unrelated, accidents.

The economic benefit and risk reduction ascribed to each risk control options is be based on the event trees developed during the risk analysis and on considerations on which accident scenarios would be affected. Estimates on expected downtime and repair costs in case of accidents should be based on statistics from shipyards or responsible government institution for repair or construction.

This CBA is then followed by assessment of the control options as a function of their effectiveness against risk reduction. In estimating $\mathrm{RCO}$, the following are taken into consideration:

i. DALY (Disability Adjusted Life Years) or QALY (Quality Adjusted Life Years)

\section{ii. LQI (Life Quality Index)}

iii. GCAF (Gross Cost of Averting a Fatality)

iv. NCAF (Net Cost of Averting a Fatality)

The common criteria used for estimating the cost effectiveness of risk reduction measures are NCAF and GCAF which can be calculated with the following equation:

$$
\begin{aligned}
& \text { Gross CAF }=\frac{\Delta \mathrm{C}}{\Delta \mathrm{R}} \\
& \text { GCAF }=\frac{\text { Cost-Benefit }}{\text { Reduction }} \\
& \text { NET CAF }=\frac{\Delta \mathrm{C}-\Delta \mathrm{B}}{\Delta \mathrm{R}}
\end{aligned}
$$

$\mathrm{NCAF}=\mathrm{GCAF}-$ Change in Benefit

Eq. 5

$\mathrm{ICAF}=\frac{\mathrm{NCAF}}{\mathrm{R}}$

Eq. 6

Where: $\Delta R$ is Reduction in annual fatality rate, $\Delta R$ is Economic benefit resulting from implementing the risk control option, $\Delta \mathrm{R}$ is Risk reduction in term of averted number of fatality implied by the risk control option.

NCAF and GCAF depend on the following criteria:

i. Observation of the willingness to pay to avert a fatality;

ii. Observation of past decisions and the costs involved with them;

iii. Consideration of societal indicators such as the Life Quality Index (LQI).

In RCO, It is important to address the following:

i. Primary cause or accident scenario, number of accident

ii. Number of losses, number of life loss per accident

iii. Cost of fatality per accident, average total cost per accident

Cost per unit risk reduction $(\mathrm{CURR})=\frac{\text { Cost }- \text { Benefit }}{\text { Reduction }}=$ NPV

Benefit

Eq. 7

Where 50 minor injuries $=10$ serious injuries $=1$ life $=$ property or damage $=$ loss or degradation of environment.

\section{B. Net Present Value (NPV)}

The NPV can be calculated from:

$$
\mathrm{NPV}=\sum_{\mathrm{t}=1}^{\mathrm{n}}\left[\left(\mathrm{C}_{\mathrm{t}}+\mathrm{B}_{\mathrm{t}}\right)\left(1+(1+\mathrm{r})^{-\mathrm{t}}\right]\right.
$$

Where: $\mathrm{t}=$ Time horizon for assessment, starting in year 1 , Number of year in vessel life time, $B=$ the sum of benefit in period, $r=$ the discount rate per period, Ct- sum of cost in period.

The estimated risk is represented by:

$\mathrm{R}_{0}=$ Accident frequency $\mathrm{Na}$ or $\mathrm{P}$ (Number of ships per year) x Consequence $\mathrm{C}$ x (Cost of damage per accident) Risk after implementation of safety measure.

$R_{1}=$ Accident frequency $P$ (Number of ships per year) $\mathrm{x}$ Consequence $\mathrm{C} x$ (Cost of damage per accident)

Benefit of reduced risk $(R)=R_{0}-R_{1}$

NPV of the benefit for estimated risk and implemented safety measure is calculated and ratio of cost of $\mathrm{C}$ to benefit $\mathrm{B}$ is compared and expected to be $<1$.

\section{Implied Cost of Averting Fatality (ICAF)}

ICAF represent estimation of benefit of avoiding damage or fatality. It plays important role in cost benefit analysis of risk. ICAF can be estimated using the following means ( $\mathrm{DnV}$, 2005):

Ronold Life quality index $(\mathrm{L})=\mathrm{Y}^{\mathrm{w}} \cdot \varepsilon^{1-\mathrm{w}}$

Eq. 10

Where: $\mathrm{L}=$ life quality index, $\mathrm{Y}=$ Gross domestic product per person per year, $\varepsilon=$ Life expectancy (year), $\mathrm{w}=$ Proportion of life spent in economic activities in developing countries is approximately $1 / 8$.

Optimal acceptable ICAF $=>|\Delta \gamma|_{\max } . \Delta \varepsilon=\frac{Y-\epsilon}{4} \cdot \frac{1-\mathrm{w}}{\mathrm{w}}$ Eq. 11

Where, Social cost $=\mathrm{NC}(1+\mathrm{i})^{\mathrm{t}}, \mathrm{t}<6000$, Social cost $=$ 
$\mathrm{NC}(1+\mathrm{i})^{6000}, \mathrm{t}>6000, \mathrm{~N}=$ number of injuries or fatalities, $\mathrm{C}=$ Cost of damage per day depends on types and countries, $\mathrm{I}$ $=$ daily rate of interest, $\mathrm{T}=$ Duration of damage or sick leave in day, 6000 days is equivalent with a fatality, DNV $=$ US\$ 3 million $=$ cost effective $\mathrm{ICAF}$ rate $=2 \mathrm{GBP}$ million $=$ developed country. $\Delta \varepsilon=\frac{\varepsilon}{2}=1 / 2$ of life expectancy, largest change in GDP, $|\Delta \gamma|_{\max }=-y .(1-\mathrm{w}) / 2 \mathrm{w}$.

\section{Damage or Loss of Life Quantification}

Ship collision is rare and independent random event in time. The event can be considered as poison events where time to first occurrence is exponentially distributed (Emi et al, 1997).

$$
\mathrm{f}(\mathrm{t})=\gamma \mathrm{e}^{-\gamma \mathrm{t}}
$$

Where: $Y=$ Annual rate of exceeding of consequence energy capacity, $\mathrm{t}=$ the time to the future loss

$$
\mathrm{C}_{\mathrm{o}}=\mathrm{C}_{\mathrm{f}} \cdot \int_{0}^{\mathrm{T}} \mathrm{e}^{-\mathrm{it}} \cdot \mathrm{\gamma}^{-\mathrm{dt}} \cdot \mathrm{dt} \quad \text { Eq. } 13
$$

Total cost $\mathrm{C}_{\mathrm{t}}=$ present value of future cost $\left(\mathrm{C}_{\mathrm{O}}\right)+$ Cost of protective measure $(\mathrm{Cc})$

$$
\mathrm{C}_{\mathrm{t}}=\mathrm{Co}+\mathrm{Cc} \quad \text { Eq. } 20
$$

In prioritizing alternative under (RCBA), it is important to address the following: Available concept, consequence energy capacity (MJ), Return for exeedance T (Year) as well as:

Annual rate of exeedance $\left(\gamma=\frac{1}{\tau}(-)\right.$

Eq. 14

The cost effective risk reduction measures should be sought in all areas. It is represented by followed:

Acceptable quotient $=$ Benefit $/($ Risk $/$ Cost $)$

Eq. 15

\section{E. Sustainability Analysis}

Sustainability is defined as development work that meets needs of the present generation without compromising the ability of the future generations to meet their own needs. It requires balancing work between technical, developments, economic, community participation, information sharing, environment and safety. Suitability principle calls on all fields of human activities to review and adjust the way things are done. At its 21st session in February 2001, the UNEP governing council adopted a decision to investigate the feasibility of a "Global Assessment of the State of the Marine Environment" UNEP GC Decision 21/13 [12].

\section{F. Decision Making}

Decision making involves discussion of hazard and associated risks, review of RCO that keep ALARP curve in acceptable region, compare and rank $\mathrm{RCO}$ based on associated cost and benefit. It also involves specification of recommendation for decision makers towards beyond compliance preparedness. And rulemaking tools for regulatory bodies towards measures and contribution for sustainable system design. RCO provide measures, outcome of objective comparison of alternative option, and subsequent contribution recommendation for sustainable implementation need of the system intactness, the planet and the right of future generation.

\section{RESUlt AND DISCUSSION}

\section{A. ALARP risk curve for changing}

Figure 4a shows accident consequence accident energy and accident occurrence frequency against all waterway parameters, the meeting pint signify the optimum operating point. But that need to be investigated if it is cost effective.

\section{B. Identified Risk Control Options to Reduce the Collision, Grounding and Contact}

RCO for each collision situation has to be more clearly defined. In order to identify new RCO, generated result from the analysis of frequency and consequence, cost and benefit is weighted. It is important to support this with expert rating to contribute to possible risk prioritisation control options for IWT of on Sungai Langat. The descriptions of the major hazards and corresponding risk control options from the hazard identification and the results from the risk analysis which are summarised could be presented to the group of experts for further validation. From the risk study, prioritized RCO that were selected for further evaluation in terms of cost effectiveness assessment are discussed in the next paragraph. Even thus this research is about collision, the impact to collision is not far from contact and grounding collision scenario. Therefore some of the measure that will be taken could benefit curbing accident from contact and grounding. The main RCO`S are:

i.Improved navigational safety.

ii. Redundant propulsion system: two shaft lines.

iii.Required maintenance plan for critical items as well design requirement for increase double hull width, increase double bottom depth or increase hull strength.

iv.Human factor and human reliability is quite critical in risk work, it need to be done separately.

\section{RCO 1: Improved Navigational Safety}

Improved navigational safety can be achieved in a number of different ways. From various identified risk control options, five cost effective risk control options for navigation improvement that could potentially reduce the frequency of collision and grounding which are:

\section{i. TSS}

ii. ECDIS (Electronic Chart Display and Information System), track control system,

iii. AIS (Automatic Identification System) integration with radar

ivImproved bridge design

The risk control options related to navigational safety in the list above might be promising alternatives for Langat River. The cost effectiveness of implementing this measure for Langat River is evaluated in this study. Hence, the risk control option for improved navigational safety is defined as implementation of one or more of the above alternatives. Installation of valve control radar can reduce risk of oil spill due to overfilling, malfunction of a valve or human failure among other causes. The levels of storage tanks on board must be continuously monitored since overfilling or product discharge on deck could have consequences for human life and for property. 


\section{RCO 2: Redundant Propulsion System}

Machinery failure is a significant causal factor in collision accident. Collision can be avoided if the ships had redundant propulsion or steering systems. The redundant propulsion and steering system must ensure that, irrespective of the ship's loading condition, when a failure in a propulsion or steering system occurs:

i. The maneuverability of the ship can be maintained.

ii. A minimum speed can be maintained to keep the ship under control.

iii. The ship can maintain operation with a redundant propulsion or steering system so that a vessel can ride out the storm or slow navigation in port.

iv. The propulsion and steering functions are quickly re established.

Cost effectiveness assessment for redundant propulsion systems will be achieved by installation of independent engines and two shaft lines. The use of all electric propulsion could be a good advantage for optional navigation mode. This would also have effect on different hull forms compared to ships with single propellers.

\section{E. RCO 3: Human Capital Development}

Discussion with waterways authority revealed that only the captain's qualification and competency is being screened and regulated. It is recommended to institutional screen on certification and competency of all officers on the vessels and to undergo simulation for normalization of behavior. This risk control option aims at increasing the bridge team's ability to handle difficult maneuvering tasks and crisis situations by increased use of simulator training. The effect of such training could provide better navigational safety and a reduced risk of collision, grounding and contact events. The simulator training could be specially designed for particular port environments, underwater topography, and particular bridge layouts on specific vessels and would give the participants exercises in handling challenging situations from different positions of the bridge team. Important parts in such exercises might be passage planning, situation awareness and operation during malfunction of critical technical equipment. The risk control option suggested herein goes beyond the basic training requirements defined by IMO's International Convention on Standards of Training, Certification and Watch keeping for Seafarers (STCW), (IMO, 1996).

\section{F. Sustainability Analysis and Cost Effectiveness of Selected RCOs}

Risk Cost Benefit Analysis to deduce and proposed need for new regulations based on mitigation and options selection RCBA involve quantification of cost effectiveness that provides basis for decision making about RCO identified, this include the net or gross and discounting values. Consideration is also given to cost of equipment, redesign and construction, documentation, training, inspection maintenance, auditing, regulation, reduced commercial used, operational limitation like speed and loads. Benefit could include reduced probability of fatality, injuries, serenity, negative effects on health, severity of pollution, economic losses.

Cost work is model in different way, and translation of quantity is allowed between benefit, damage, oils spill, fatality. For this case, based on estimate on the level of damage, 1 fatality is considered due to frequency of accident. Figure 5a show that at minimum energy of $20 \mathrm{MJ}$, less 700 , 000 RM gross costs will be required to avert fatality. Whereas, at $400 \mathrm{MJ}$ energy of impact 2.07 million RM gross cost will be required to avert fatality. Figure $5 \mathrm{c}$ shows that $731000 \mathrm{RM}$ will be ICAF required at minimum accident energy released of 20MJ while, 2.53 million will be the ICAF of released energy of $453 \mathrm{MJ}$. Figure $5 \mathrm{~b}$ shows that 1.47 million net cost will be required to avert fatality at minimum energy of 20MJ, 2,8 million RM will be required to avert fatality at catastrophic accident energy of 453MJ. Figure 7 depicts the cost of losses per accident causal factors. Propulsion failure carry the highest (RM 2,000,000) follow by loss of navigation function which require about RM 700, 000 and about 400, 000 will be require to fix human error problem. These costs are still acceptable as long as they are less than 3 million.

All numbers are based on introduction of one RCO. Introduction of more than one $\mathrm{RCO}$ will lead to higher NCAF and GCAFs for other RCOs addressing the same risks. High GCAF and NCAF values indicate that the considered RCO is not a cost effective measure. A negative NCAF indicates that the RCO is economically beneficial in itself, For example the costs of implementing the RCO are less than the economical benefit of implementing it. From the Figure, number of accident and loss of life are considered low. According to current practice within IMO and selected criteria for this study, a risk control option will be regarded as cost effective if it is associated with GCAF $\leq$ USD 3 million or NCAF $\leq$ USD 3 million. Cost effective measures that can be demonstrated to have a high potential for risk reduction will consequently be recommended for implementation. ICAF represent estimation of benefit of avoiding damage or fatality and it ply important role in cost benefit analysis of risk. This can be estimated using the following means.

\section{G. Sustainability}

Figure 6 show it cost much more to implement navigation and machineries failure system. The maximum cost is indicated by the point where the total cost $(\mathrm{Ct})$, the present value of loss, and NPV coincide, about RM30 million, where the cost of unit risk reduction still stand at about RM2000, 000. Figure 222 shows cross plot of the risk level and optimal cost require for the channel maintenance. From this Figure it is observed by spending more than 50Million, high speed craft or freighter of 35 knot will be able to navigate on Langat River in future. According to recent discussion with Langat River, a decision is already made no pass the bridge over the river. Therefore for Langat River that need to be included in analysis, but benefit could be quantify into cost.

\section{REFERENCES}

[1] DnV. Formal Safety Assessment of cruise navigation. DNV Report No. 2003-0277, Det Norske Veritas, Høvik, Norway. Norway, 2005

[2] Kite, Powell, H. L., D. Jin N. M. Patrikalis, J. Jebsen, V. Papakonstantinou. Formulation of a Model for Ship Transit Risk. MIT Sea Grant Technical Report. Cambridge, MA. 1996. 96-19.

[3] Skjong, R., Vanem, E., Endresen, Ø. Risk. Evaluation Criteria. SAFEDOR report D. 2006 
[4] Lempert, R. J., S. W. Popper and S. C. Bankes. Shaping the Next One Hundred Years: New Methods for Quantitative Long-Term Policy Analysis. RAND:Santa Monica, CA. 2003. pp. 187.

[5] Roach, P.J. Verification and Validation in Computational Science and Engineering. Hermosa Publishers. Albuquerque. NM, 1998.

[6] Coleman, H.W., W.G. Steele, Jr. Experimentation and Uncertainty Analysis for Engineers. John Wiley \& Sons. 1989.

[7] Kitamura, O. FEM approach to the simulation of collision and grounding damage. In Proceedings of 2nd International Conference on Collision and Grounding of Ships July 2001, pp. 125-136 (Maritime Engineering, Department of Mechanical Engineering, Technical University of Denmark).
[8] Axtell, R., R. Axelrod, J. Epstein and M. D. Cohen. Aligning Simulation Models: A Case Study and Results. Computational and Mathematical Organization Theory. 1996. pp123-141.

[9] Yacov T. Haimes. Risk Modeling, Assessment and Management. John Wiley \& Sons, INC. Canada. 1998. pp. 159 - 187.

[10] N. Soares, C. A. P. Teixeira. Risk Assessment in Maritime Transportation. Reliability Engineering and System Safety. 74:3, 2001, 299-309.

[11] Fujii, Y. and Mizuki, N. Design of VTS system for water with bridges In Proceedings of Ship Collision Analysis (Eds H. Gluver and D. Olsen), 1998, pp. 177-190 (Balkema, Rotterdam)

[12] Camm, Jeffrey D. \& Evans, James R. Management Science \&Decision Technology. South-Western College Publishing, 2000.

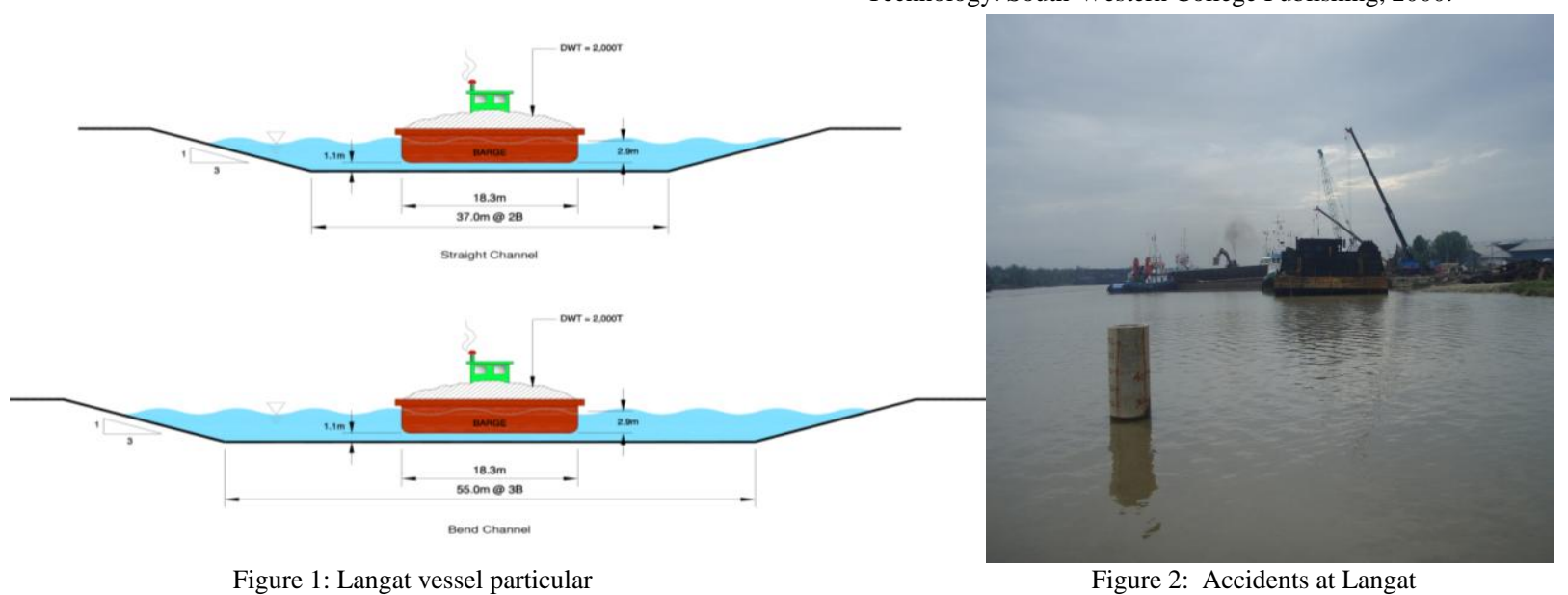

TABLE 1: RISK BASED DESIGN TECHNIQUES

\begin{tabular}{|l|l|}
\hline Process.r & Suitable techniques.r \\
\hline HAZID.r & HAZOP, What if analysis, FMEA, FMECA.r \\
\hline Risk analysis.r & Frequency, consequence, FTA, ETA.r \\
\hline Risk evaluation.r & Influence diagram, decision analysis.r \\
\hline Risk control option.r & Regulatory, economic, environmental, function elements matching and iteration.r \\
\hline Cost benefit analysis.r & ICAF, Net Benefit.r \\
\hline Human reliability.r & Simulation/ Probabilistic.r \\
\hline Uncertainty.r & Simulation probabilistic.r \\
\hline Riskmonitoring.r & Simulation/ probabilistic.r \\
\hline
\end{tabular}




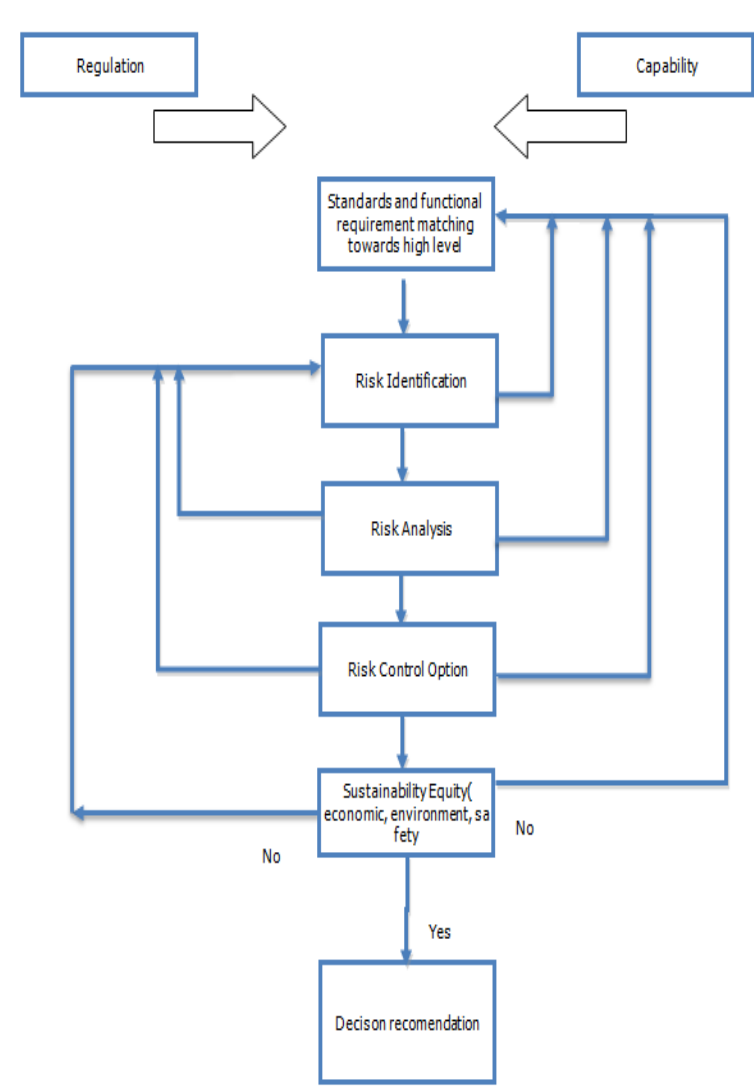

a.Serm model

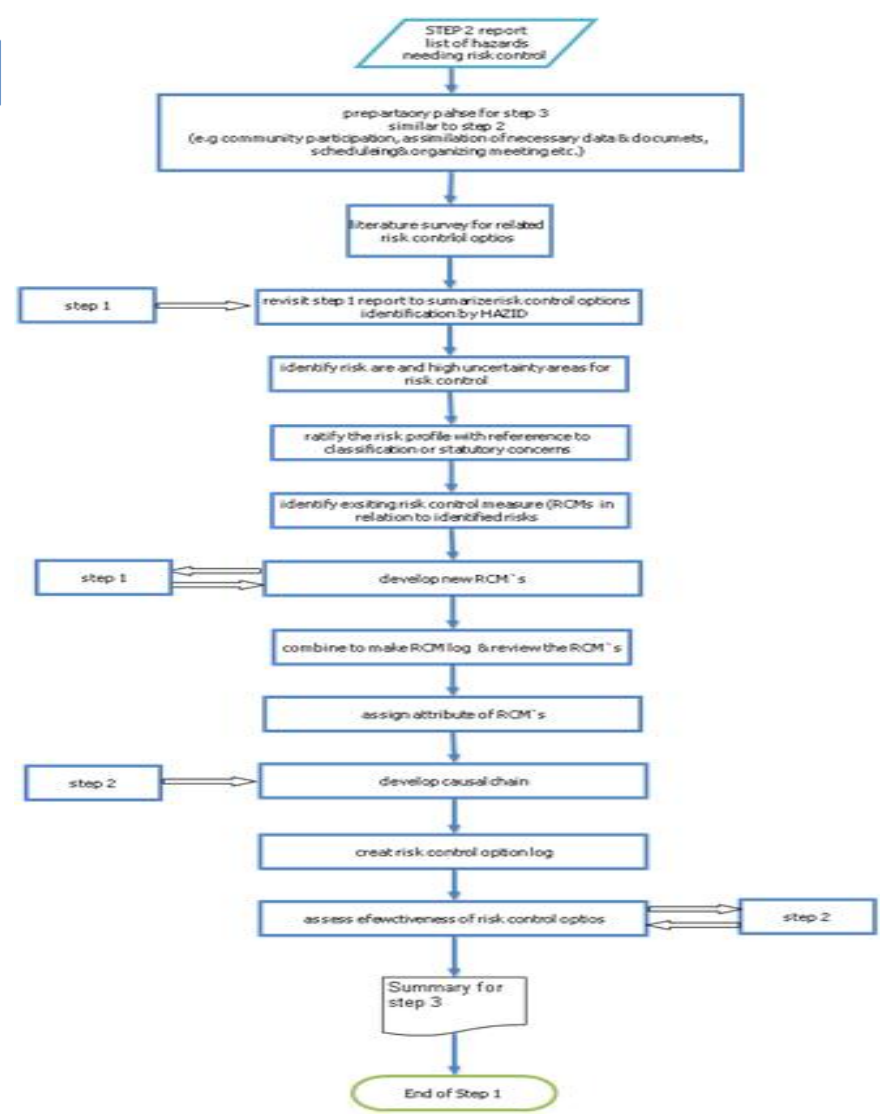

b. Cost benefit sustainability analysis

Figure 3: Risk and Reliability model flowcharts

$\mathrm{Fa}$

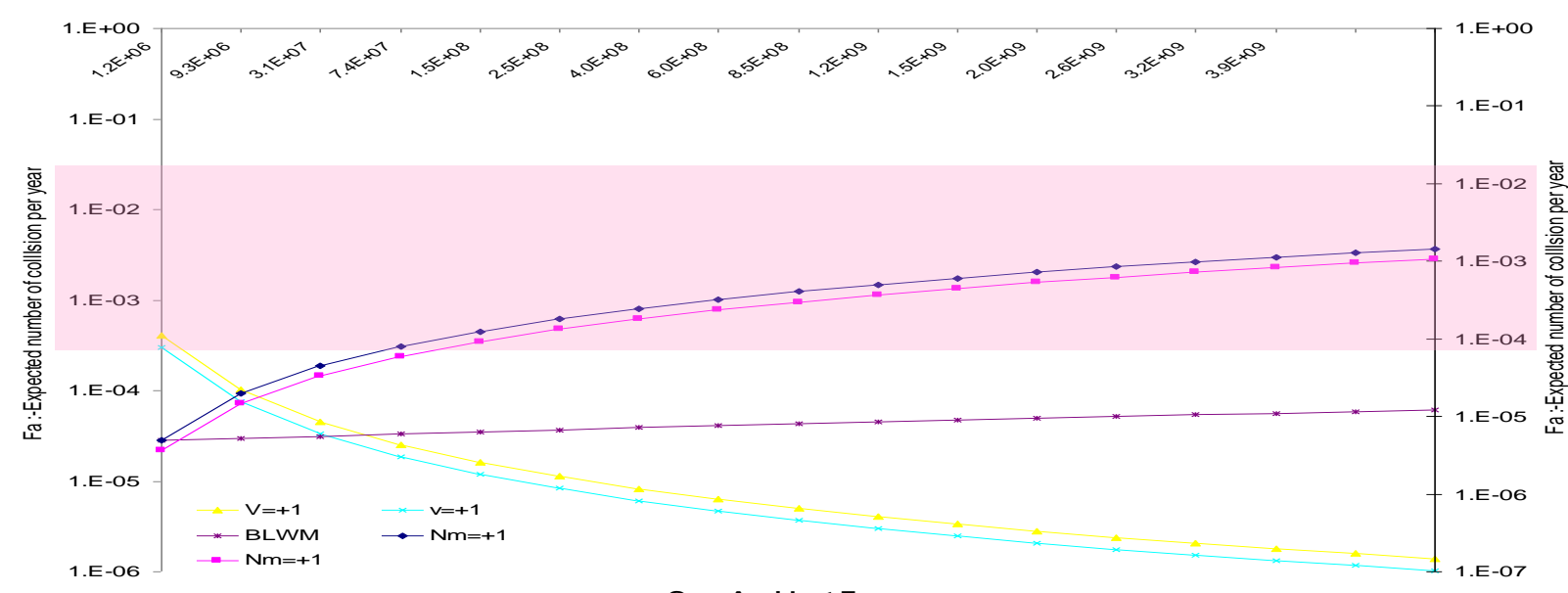

Figure 4: Accident energy Vs consequence energy

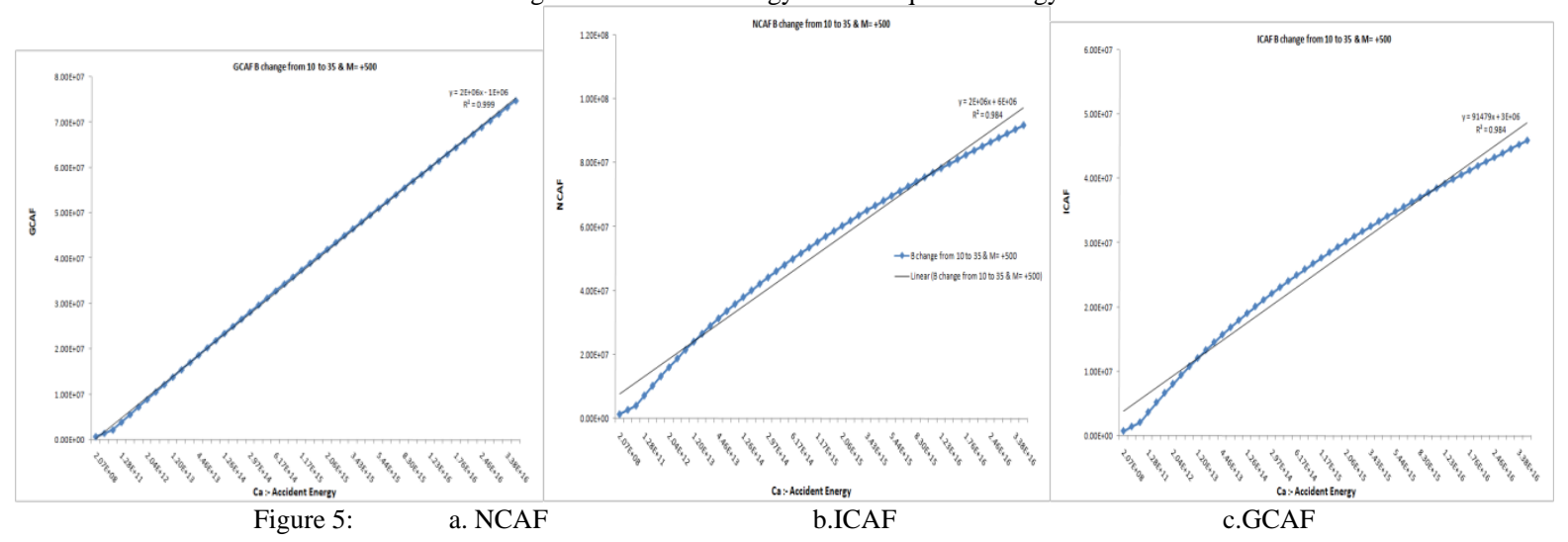


International Journal of Trade, Economics and Finance, Vol.2, No.1, February, 2011

2010-023X
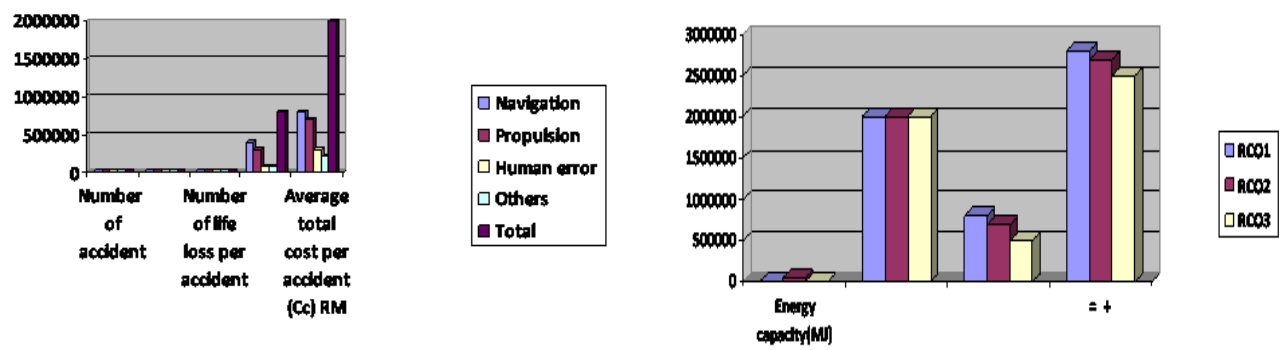

Figure 6: Cost of losses per accident causal factors, Figure: 20: RCO`s analysis for total cost of damage Co Cc \& Ct vs Fa

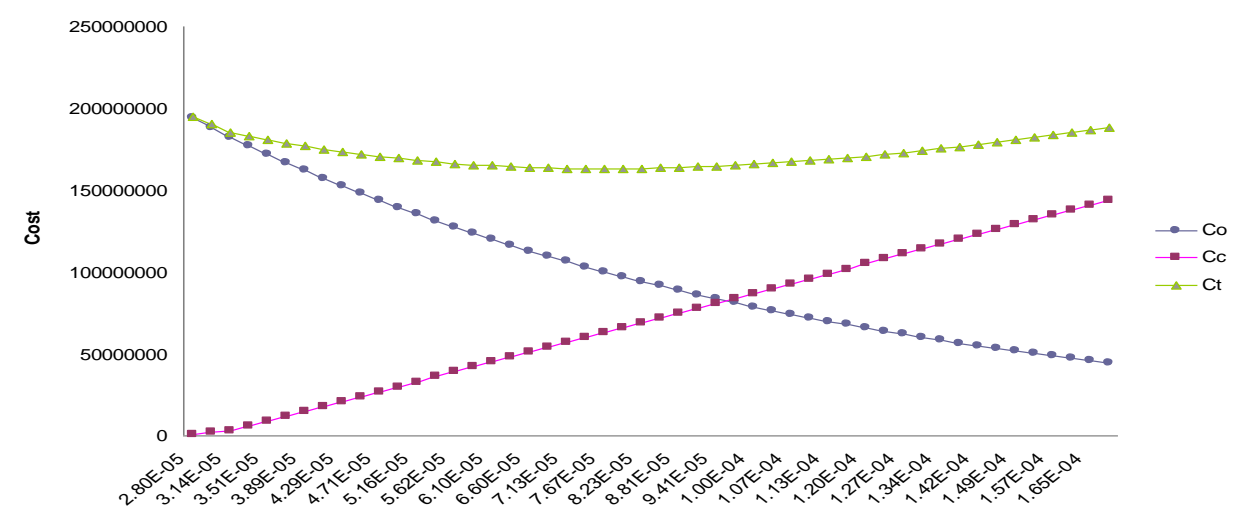

Figure 7: Risk cost benefit analysis 